\title{
SEX DIFFERENCES OF PARVALBUMIN-IMMUNOREACTIVE NEURONS IN THE RAT BRAIN
}

\author{
Nadya Stefanova, Anastassia Bozhilova-Pastirova, and Wladimir Ovtscharoff \\ Department of Anatomy and Histology, Medical University, Sofia, Bulgaria
}

- During the last two decades numerous studies have proven the existence of sexual dimorphism in the brain of lower vertebrates, birds, and mammals. Differences between males and females have been found in various components of central nervous system (CNS), including volumes of certain nuclei, numbers of neurons and synaptic contacts, size of somata and outgrowths, as well as differences in neurolransmitter systems. The mechanisms by which these dimorphic features appear remain an open question for further elucidation. It is not clear yet how the morphological variations observed between sexes during development could be related to functional consequences in the adult organism.

\section{SEXUAL DIFFERENTIATION OF THE BRAIN: CONCEPTS AND HYPOTHESES}

- Studying the mechanisms of sexual differentiation of the CNS is necessary for understanding the process of neural development. The early embryonic nervous system is considered bipotenlial (1). Whether it will differentiate into male or female

\section{Biomed Rev 1997; 7: $91-96$}

Received for publication 17 July 1997 and accepted 3 November 1997. Correspondence and reprint requests to Dr Anastassia BozhilovaPastirova, Department of Anatomy and Histology, Medical University, 2 Zdrave Street, BG-1431 Sofia, Bulgaria. Tel: 359 (2) 518 623,Fax: 359 (2) 518783 ,

E-mail: bolzilov@mediae.acad.bg depends on sex chromosomes and environmental stimuli that could influence this process. The sex chromosomes determine the formation of ovaries or testes and thus the production of female or male sex steroids. According to the androgen theory of sexual differentiation (Fig. 1), androgens are required for the formation of male type nervous system. Interestingly, when androgens enter the neurons they may be aromatized to estradiol-17(3, and the latter is actually responsible for the masculinization of the brain (2). On the other hand, females are thought to be protected by this process through binding between alpha-fetoprotein and estrogens (1) and thus escaping masculinization. All these events that determine the faith of neural differentiation take place during a critical period of CNS development (3). Recently, several studies have dealt with extending the classical "organizational" concept and suggesting new regulatory mechanisms underlying sexual differentiation of the brain (4). In general, sex-specific properties could be regulated by the interference of other factors like neurotransmitters or growth factors with the effect of sex steroids. On the other hand, it is possible that some sexually dimorphic features may develop under primary genetic control. This idea is supported by results obtained from sex-specific cell cultures of embryonic rat brain, showing that dopaminergic neurons develop morphological and functional sex differences in the absence of cstrogen or testosterone (5). Additionally, it is proposed that sex-determining region of the Y chromosome (Sry gene) is transcribed in male but not female mice brain and plays a role in the regulation of sex differentiation of the mammalian CNS (6). Irrespective of the exact mechanisms of sexual differentiation, studies on sexual di- 


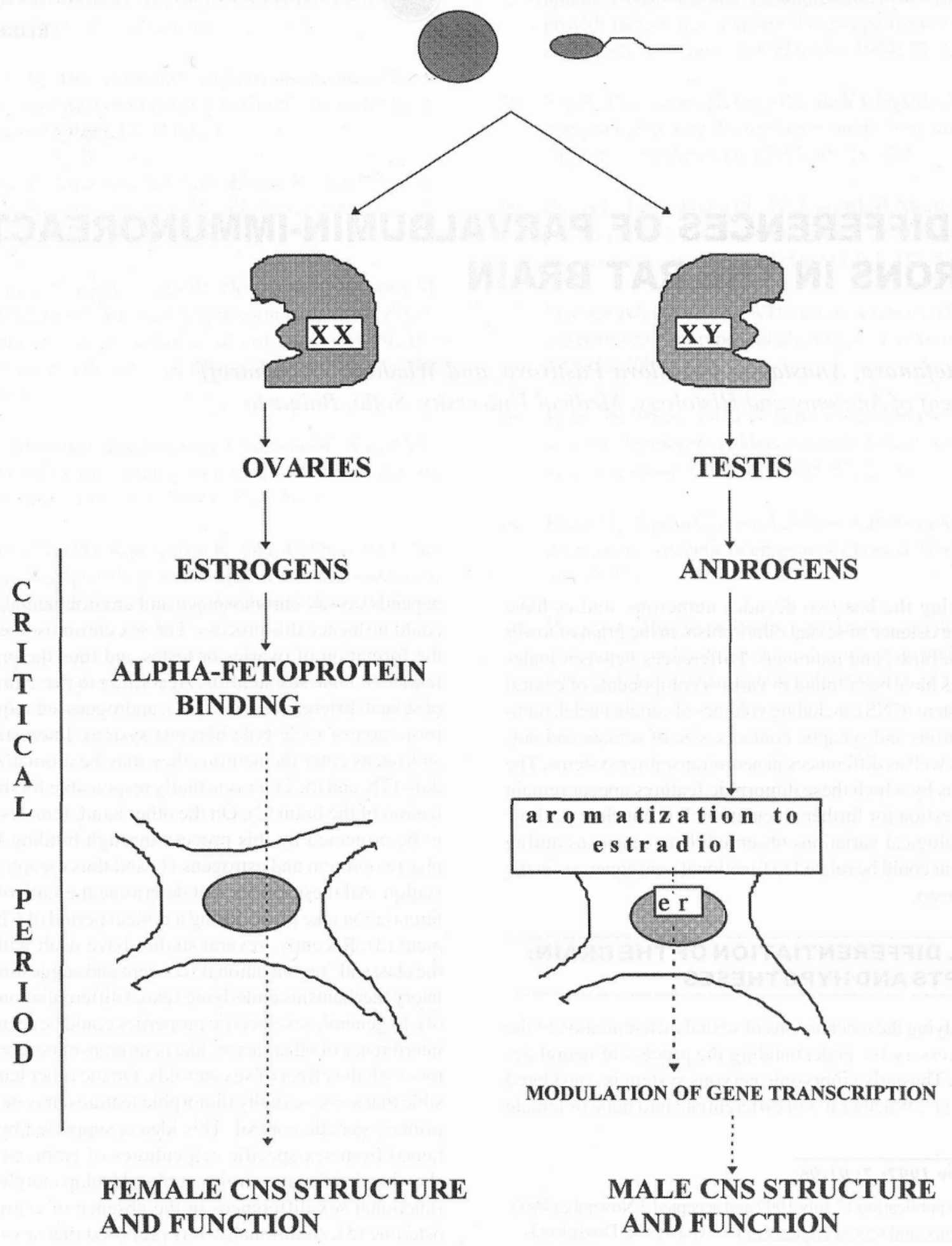

Figure 1. Scheme of the androgen hypothesis of brain sexual differentiation, showing that androgens, after dramatization in the brain, masculinize the brain through estradiol. er, estrogen receptor; CMS, central nervous system. 
morphism of the brain are necessary and important for the explanation of dimorphic functions and their underlying neural circuitry.

\section{GAMMA-AMINOBUTYRIC ACID AND SEXUAL DIMORPHISM}

- Gamma-aminobuly ric acid (GAB A) is an important inhibitory neurotransmitter in the CNS of vertebrates. It can be found in inlerneurons as well as in projection neurons of various brain areas (reviewed in 7). Information processing in the CNS through GABA can be accomplished by inhibition and disinhibition, depending on the synaptic connections of GABAergic neurons. Recently, GABAergic system has been associated with the realization of some aspects of male and female reproductive behaviors and neuroendocrine functions. It has become evident that GABA is involved in steroid induced negative feedback control of luteinizing hormone-releasing hormone (8) and plays a critical role in the modulation of gonadotropin and prolactin release from the pituitary gland (9-11). GABA participates in the neural circuitry controlling lordosis behavior. It has been shown that GABA has dual effects, i.e. facilitation of lordosis through acting in the medial hypolhalamus and the midbrain central grey and inhibition of lordosis through actions in the preoptic area (12. 13). The precise source of GABAergic neurons innervating these regions remains unclear. Hence, studying the GABAergic system may help elucidating the mechanisms of female sexual behavior. Maternal behavior is also connected with the functioning of the GABAergic system. An implication of $\mathrm{GABA}_{\mathrm{A}^{-}}$ bcn/odiazepine- $\mathrm{Cl}$ " receptor complex in the development of maternal behavior in female rats has been discribed (14). The contribution of cell loss in the vomeronasal system, including loss of GABAergic neurons, to facilitation of this behavior has been discussed (14). GABA inhibitory mechanisms also regulate male sexual behaviors. Likewise, corticosterone mediates the stress-induced inhibition of male sexual behavior through the GABAergic system $(15,16)$.

The discovery of GABA involvement in the control of neuroendocrine functions and reproductive behaviors in a sex-specific manner has led to the proposal of sexual dimorphism of the GABAergic system itself. Such a dimorphism could further be associated with sex differences in other functions, i. e. motor control, learning and memory. Sexual dimorphism of GABA-immunoreactive neuronal densities in the prenatal rat striatum (17), in postnatal striatum (18) and in the bed nucleus of stria term.ina.lis (19) has been established. Gender dimorphism and dependence on sex steroids arc also observed in enzymes taking part in GABA metabolism, e. g. glutamic acid decarboxylase (20) and GAB A-transaminase $(21)$. Studies on $\mathrm{GABA}_{\mathrm{A}}$ receptor ligation in the rat brain have revealed gender difference at this point of GABAergic neurotransmission, too (22)
It is known that in the majority of GABAergic neurons, GABA coexists with different neuropeptides, such as cholecystokinin, somatostatin, enkephalins, substance $\mathrm{P}$, and opioid peptides. In this way certain subpopulations could be formed within the GABAergic neurons, which could have different implications to the formation of sexually dimorphic functions. Since the data available allows us only to speculate on this problem, the functional involvement of different GABAergic subpopulations needs to be further clarified.

\section{PARVALBUMIN: A MARKER OF GABA- ERGIC NEURONAL SUBPOPULATION}

- Pan/albumin (PA) (L.parvus small, albumin-like protein) is a prototype member of the family of EF-hand calcium-binding motif-containing proteins. It has been first isolated from the muscles of lower vertebrates and functionally associated with the relaxation of fast-contracting skeletal muscles (23). PA is also present in other nonmuscle cells, especially nerve cells (24-28). Colocalization studies have shown that PA-immunoreactive neurons usually form a separate subpopulation of GABAergic neurons $(29,30)$. This subpopulation includes possible local circuit neurons, but according to Freund (31), some projection GABAergic neurons in the septo-hippocampal region also contain PA. Additionally, thalamic projecting PA-containing neurons have also been described (32). Therefore, PA-containing cells can be either local circuitry interneurons, or projection neurons.

PA-immunoreactive neurons usually appear after the first postnatal week of development, in different terms for various brain regions (33; Stefanovaef a/, unpublished data). It probably correlates with the appearance of the related functional activity in different regions, and the inhibitory activity as well.

\section{PARVALBUMIN-IMMUNOREACTIVITYAND SEXUAL DIMORPHISM}

- It is interesting to find out whether the subpopulation of PA-immunoreactive neurons is affected by gender, and further to answer the question of functional implication of this particular group of GABAergic neurons in the formation of sexual behaviors as well as other sexually dimorphic functions. In our recent studies we have used monoclonal PA-antibodies and avidin-biotin complex method to describe the distribution and density of PA-immunoreactive neurons in different parts of the CNS, that either are associated with the realization of reproductive behaviors, or show gender dimorphism in their total GABAergic neuronal population. It has been proved that the influence of sex on PA-immunoreactive neurons has certain regional variations in the rat brain at postnatal day 20 (Fig. 2). The striatum, a structure which is a key center of motor control and has proven gender dimorphism in its GABAergic neuronal 
density, shows also sexually different numbers of PA-immunoreactive neurons. Females have greater numbers of immunoreactivc profiles than males. Quite different is the proportion of male to female PA-immunoreactive neurons in two other sexually dimorphic structures with wide contribution to the formation of reproductive behaviors, i.e. the amygdaloid complex and the hippocampal formation. Neuronal counts exhibit no significant sex difference in the medial amygdaloid nucleus and the hippocampus. The cortical amygdaloid nucleus possesses sexual dimorphism but it is in the opposite direction compared to the striatum. That is, male rats have greater numbers of PA-immunoreactive neurons than female rats. The same gender correlation has been observed in the nucleus accumbens, which is a part of the ventral striatum and is amain structure in the mesolimbic dopamincrgic system involved in male sexual behavior (34).

\section{CONCLUSION}

- The present Dance Round describes sexual dimorphism of a definite PA-containing subpopulation of GABAergic neurons in the rat brain. The different pattern of PA-immunoreactivity in certain brain structures of both sexes could be a key for further investigations on the involvement of GABAergic neurotransmitter system in controlling the of reproductive behavior and other sexually dimorphic functions. Furthermore, PAimmunorcactive neurons are found to be affected by several diseases, including Creutzfeklt-Jakob disease (35), Alzheimer's disease $(36,37)$, epilepsy (38), and amyotrophic lateral sclerosis (39). Perhaps, by studying the system of PA-immunoreactive neurons it would be possible to explain sex-specific prevalence in patients with such disorders and to improve our understanding about their pathogenesis. The mechanisms by which sexual dimorphism in PA-immunorcactive neurons appear are not yet clarified. Indeed, there is much to be learned about how and when during ontogenesis these gender differences occur and what is the role of sex steroids in the regulation of PA-containing neuronal subpopulation. , $-, \ldots, ;$.

\section{REFERENCES}

1. Kelly DD. Sexual differentiation of the nervous system. In:

Kandel ER, Schwarz JH, editors. Principles of Neural Science. Elsevier, Amsterdam. 1991; 960-973

2. Hulchison JB. Hormonal control of behavior: steroid action in the brain. Curr Opin Neurobiol 1990; 1: 562-570

3. Rhees RW. Shryne JE, Gorski A. Onset of hormone-sensitive perinatal period for sexual differentiation of the sexually dimorphic nucleus of thepreoptic area in female rats.

.. $N \ll<\mathrm{raWo} / 1990: 21: 781-786$

4. Pilgrim C, Hutchison JB. Developmental regulation of sex

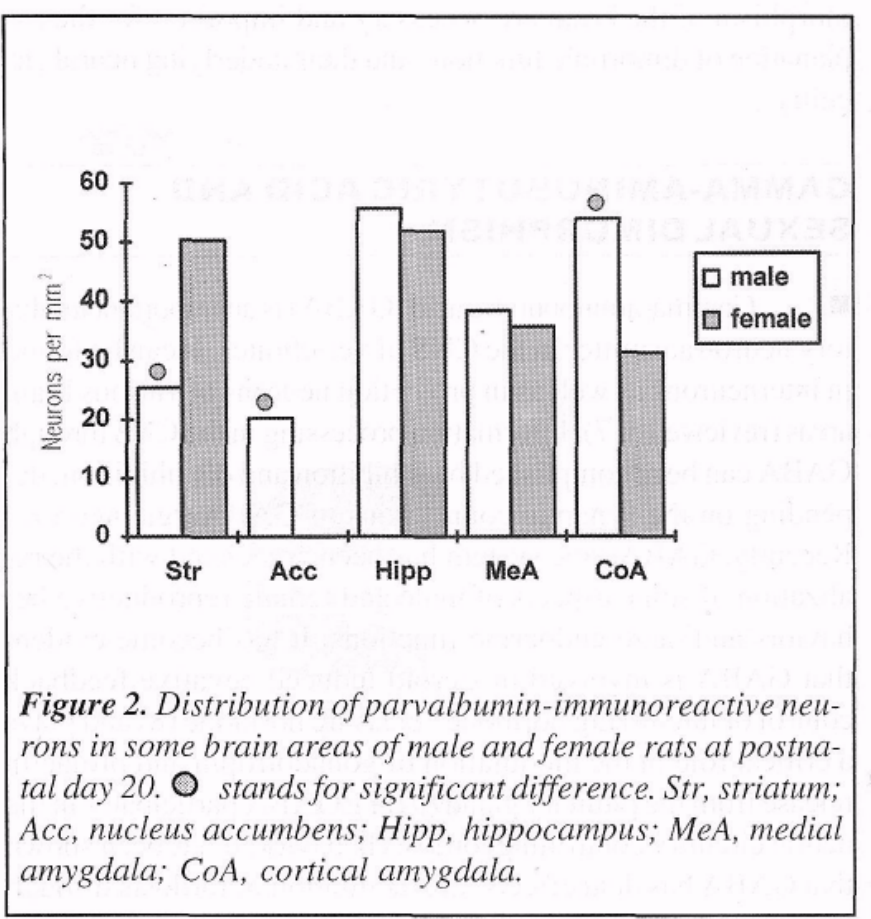

differences in the brain: Can the role of gonadal steroids be re-defined?Neurosclence 1994; 60: 843-855

5. Reisert I, Pilgrim C. Sexual differentiation of monoaminergic neurons - genetic or epigenetic? Trends Neurosci 1991; 14:468-473

6. Lahr G, Maxson SC, Mayer A, Just W, Pilgrim C, Reisert I. Transcription of the Y-chromosomal gene, Sry, in adult mouse brain. Mol Brain Res 1995; 33: 179-182

7. Mugnaini E, Oertel WH. Atlas of the distribution of GABAergic neurons and terminals in the rat CNS. In: Bjorklund A, HokfeltT, editors. GABA andNeuropeptides in the CNS. Parti. Elsevier, Amsterdam, 1985; 571-573

8. Grattan DR, Selmanoff M. Regional variation in yaminobutyric acid turnover: Effect of castration on $y$ aminobutyric acid turnover in microdissected brain regions of the malerat.JNeurochem 1993; 60: 2254-2264

9. Lieb G, Reisert I, Pilgrim C. Differentiation of hypothalamic GABAergic neurons in vitro: Absence of effects of sex and gonadal steroids. Exp Brain Res 1994; 99:435-440

10. Moguilevsky JA, Carbone S, Szwarcfarb B. Changes in the effect of gamma-aminobutyric acid on prolactin secretion during sexual maturation in female rats. Endocrinology $1992 ; 131: 458-462$ 
11. Moguilevsky JA, Carbone S, Szwarcfarb B, Rondina D. Sexual maturation modifies theGABAergic control of gonadotrophin secretion in female rats. Brain Res 1991; 563: $12-16$

12. McCarthy MM, Masters DB, Fiber JM, Lopez-Colome AM, Beyer C, Komisaruk BR et al. GABAergic control of receptivity in the female nA.Neuroendocrinology 1991; 533: 473479

13. McCarthy MM, Plaff DW, Schwartz-Giblin S. Midbrain central gray $\mathrm{GABA}_{\mathrm{A}}$ receptor activation enhances, and blockade reduces sexual behavior in the female rat. Exp Brain Res 1991; 86: 108-116

14. Del Cerro MCR, Izquierdo MAP, Perez-Laso G, RodriguezZafra M, Guillamon A, Segovia S. Early postnatal diazepam exposure facilitates maternal behavior in virgin female rats. Brain Res Bull 1995; 38: 143-148

15. Boyd SK, Moore FL. Evidence for GAB A involvement in stress-induced inhibition of male amphibian sexual behavior. Harm Behav 1990; 24: 128-138

16. NaumenkoEV, ScrovaLI. Theroleofgamma-aminobutyric acid in the inhibiting action of emotional stress on the sexual activity of mice. ProblEndokrinol 1990; 36: 60-62 (in Russian)

17. Ovtscharoff W, Eusterschulte B, Zienecker R, Reisert I, Pilgrim C. Sex differences in densities of dopaminergic fibers and GABAergic neurons in the prenatal ratstriatum. J Camp Neural $\backslash 992 ; 323:$ 299-304

18. Ovtscharoff W, Bozhilova-Pastirova A, Vankova M. Sex differences in the development of the rat striatum [abstract]. EurJMorphol 1997; 35: 62

19. Stefanova N, Bozhilova-Pastirova A, Ovtscharoff W. Distribution of GABA-immunoreactive nerve cells in the bed nucleus of the stria terminal is in male and female rats. Eur 7Wwtoc/7CTH 1997; 41: 23-28

20. McCarthy M M, Kaufman LC, Brooks PJ, Pfaff DW, Schwartz-Giblin S. Estrogen modulation of mRNA levels for the two forms of glutamic acid decarboxylase (GAD) in female rat brain. J Camp Neurol 1995; 360: 685-697

21. ShcrifF, Eriksson L., OrelandL. GABA-transaminase activity in rat and human brain: regional, age and sex-related differences. J Neural Transm Gen Sect 1991; 84: 95102
22. Juptner $\mathrm{M}$, Hiemke $\mathrm{C}$. Sex differences in $\mathrm{GABA}_{\mathrm{A}}$ receptor binding in rat brain measured by an improved in vitro binding assay. Exp Brain Res 1990; 81: 297-302

23. Rail JA. Role of parvalbumin in skeletal muscle relaxation. News PhysioLSci \996; 11 : 249-255

24. Conde F, Lund JS, Jacobowitz DM, Baimbridge KG, Lewis DA. Local circuit neurons immunoreactive for calretin, calbindin D-28k or parvalbumin in monkey prefrontal cortex: distribution and morphology. J Cornp Neurol 1994; 341:95116

25. GlezerlT, Hol'PR,LeranthC, MorganePJ. Calcium-binding protein-containing neuronal populations in mammalian visual cortex: a comparative study in whales, insectivores, bats, rodents, and primates. Cereb Cortex 1993; 3: 249-272

26. Pitkanen A, Amaral DG. Distribution of parvalbumin-immunoreactive cells and fibers in the monkey temporal lobe: the hippocampal formation. J CompNeurol 1993; 331: 37-74

27. Pitkanen A, Amaral DG. Distribution of parvalbumin-immunoreactive cells and fibers in the monkey temporal lobe: the amygdaloid complex. J Comp Neurol 1993; 331:14-36

28. Wouterlood FG, Hartig W, Bruckner G, Witter MP. Parvalbumin-immunoreactive neurons in the entorhinal cortex of the rat: localization, morphology, connectivity and ultrastructure.J/Ve«rocyto/1995;24: 135-153

29. Martinez-Guijarro FG, Blasco-Ibanez JM, Lopez-Garcia C. Postnatal increase of GAB A- and parvalbumin-immunoreactive cells in the cerebral cortex of the lizard Podarcis hispanica. Brain Res 1994; 634: 168-172

30. Cowan RL, Wilson CJ, Emson PC, Heizmann CW. Parvalbumin-containing GABAergic interneurons in the ratneosliiatum.J Comp Neurol 1990; 302: 197-205

31. Freund TF. GABAergic septohippocampal neurons contain parvalbumin.BrainRes 1989;478: 375-381

32. Magnusson A, Dahlfors G, Blomqvist A. Differential distribution of calcium-binding proteins in the dorsal column nuclei of rats. A combined immunohistochemical and retrograde tract tracing study. Neuroscience 1996; 73: 497508

33. Alcantara S, Ferrer I, Soriano E. Postnatal development of parvalbumin- and calbindin D28K-immunoreacti vities in the cerebral cortex of theraLAnatEmbryol 1993; 188: 63-73 
34. Everilt BJ. Sexual motivation: A neural and behavioral analysis of the mechanisms underlying appetitive and copulatory responses of male rats. Neurosci Behav Rev 1990; 14: 217-232

35. Ferrer I, Casas R, Rivera R. Parvalbumin-immunoreaclive neurons in Creutzfeldt-Jakob disease. Ann Neural 1993; 34: 864-866

36. Ferrer I, Zujar M.I, Rivera R, Soria M. Vidal A, Casas R. Parvalbumin-immunoreactive dystrophic neurites and aberrant sprouts in the cerebral cortex of patients with Alzheimer's disease. Neurosci Lett 1993; 158: 163-166
37. Fonseca M, Soriano E, Ferrer I, Martinez A, Tunon T. Chandelier cell axons identified by parvalbumin-immunoreactivity in the normal human temporal cortex and in Alzheimer's disease.Neuroscience 1993; 55: 1107-1116

38. DeFelipe J, Gratia- Sola R, Marco P, del Rio MR, Pulido P et al. Selective changes in the microorganization of the human epileptogenic neocortex revealed by parvalbuminimmunoreactivity. Cereb Cortex 1993; 3: 39-48

39. Nihei K, McKee AC, Kowall NW. Patterns of neuronal degeneration in the motor cortex of amyotrophic lateral sclerosis patients. ActaNeuwpathol 1993; 86:55-64 